\title{
¿Ciencias de la Documentación o especialidades de la Documentación?
}

\section{Francisco Javier García Marco}

En la editorial del número anterior analizabamos someramente el contexto social de la Documentología y el cuestionamiento paradigmático al que se ve sometida desde la Informática y la Gestión del Conocimiento. Constatábamos la necesidad de definir sus fronteras epistemológicas y su nicho de mercado científico y técnico ante los nuevos retos sociales y disciplinarios.

Así mismo, detectábamos un peligro de disgregación en la creciente especialización que se está produciendo dentro del campo de la información y la documentación. En la época de los mercados globales, cuando el acceso a los recursos humanos, financieros, energéticos y materiales es posible mediante instrumentos meramente económicos, la bases de la competitividad descansan, sobre todo, en la información y en la inteligencia de la organización y de sus recursos humanos.

Nos preguntábamos si en ese ambiente caracterizado por la explosión de actividades altamente tecnologizadas relacionadas con la información y la documentación —no olvidemos que Informática significa precisamente Ciencia de la información- la Documentología puede servir de fuerza centrípeta de ese proceso o si otros centros terminarán atrayendo hacia sí la organización de ese inmenso campo de la información documentada, como pudiera ocurrir con la interdisciplina emergente de la Gestión del Conocimiento o, si se convirtiera en una ciencia tecno-social, con la Informática.

En cualquier caso, gane quién gane esa contienda, lo que está claro es que entorno a los problemas del procesamiento social de la información está surgiendo una nueva macroárea científica y profesional que se irá articulando en los próximos años, dentro de la cual debemos buscar nuestro papel. Ese papel pivota a nuestro modesto entender entre dos puntos: a) la colaboración en la construcción del nuevo ámbito científico, y b) el desbroce y cultivo de un nicho de mercado propio para los profesionales de la documentación.

Scire. 5 : 2 (jul.-dic. 1999) 9-10. 
¿Podemos buscar orientación en nuestro entorno para nuestro proyecto? Sin duda, podemos tomar ejemplo en ciencias más antiguas con objetos de investigación muy grandes, por ejemplo, la ciencia médica.

La Medicina es, como el nuestro, un campo de saber inmenso, compartimentado en numerosas especialidades que muta aceleradamente bajo el impacto de una continua revolución tecnológica y paradigmática. A pesar de ello, la Medicina combina con éxito investigación, docencia, organización corporativa y práctica profesional en un sistema integrado de apoyos mútuos en torno al problema común de la salud humana. Como las Ciencias de la Documentación, es una ciencia con un motor de dos tiempos: el primero, comprende, el segundo, interviene - primero estableciendo una norma, después intentando instaurarla mediante tratamientos-. En definitiva, es más que ciencia y más que técnica.

La Medicina compensa así ambición científica y teórica con un enorme sentido práctico, y también pude proporcionarnos en este sentido un interesante ejemplo de conciliación y de demostración de cómo la investigacion básica y aplicada van de la mano de la práctica profesional. Esta ciencia estudia el contexto, la estructura y la dinámica del cuerpo humano, pero lo hace para resolver problemas o mejorar funcionamientos mediante la invención de técnicas de intervención.

Otro aspecto que nos interesa destacar de la ciencia médica es que ésta posee excelentes técnicas de acumulación, depuración y organización del inmenso cuerpo de conocimientos que continuamente genera. Entre ellas nos conviene destacar ahora la creación y análisis de protocolos de intervención, una de las claves metodológicas de las ciencias sociales y humanas. Frente a las leyes universales, el protocolo es sobre todo un esquema para detectar estados de un sistema e intervenir en ellos. No se pretende un diagnóstico ni una intervención única, sino que se acumulan una enorme cantidad de conocimientos y técnicas específicas adecuadas a un enorme conjunto de situaciones posibles (las distintas enfermedades, sus manifestaciones e interacciones). Sin embargo, los protocolos son comparables entre sí y evaluables en función de su eficacia y su eficiencia para un determinado contexto, permitiendo el avance de la práctica médica.

En fin, del mismo modo que en la Medicina, en la Documentología es necesario proponernos como objetivo una integración que reconoce en la diversidad y en la especialización una de sus grandes fortalezas. Recíprocamente, hemos de encontrar un solo objeto que, con ser amplio, tenga una clara unidad y nos distinga perfectamente de otros ámbitos próximos. La Medicina se concentra en el problema de salud humana y allí ha construido una plaza fuerte. Ahora bien, ¿no es la información, el dominio que muchas veces pretendemos señorear, un campo demasiado amplio? Seguiremos reflexionando sobre ello.

Scire. 5 : 2 (jul.-dic. 1999) 9-10. 